\title{
Towards a semiotic theory of style in law: a Peircean approach
}

\author{
Bettina Bor ${ }^{1}$ and Miklós Könczöl ${ }^{2 *}$ \\ ${ }^{1}$ Doctoral student, Department of Legal Philosophy, Pázmány Péter Catholic University, Budapest and ${ }^{2}$ Research fellow, \\ Institute for Legal Studies, HAS Centre for Social Sciences, Budapest \\ *Corresponding author. E-mail: konczol.miklos@tk.mta.hu
}

\begin{abstract}
This paper discusses the promises and limits of a Peircean semiotic approach to the concept of style in law. It does so in two steps: first (1) by identifying the place of style within the structure of law as a system of signs, then (2) by conceptualising the link between law and style in the thought of C.S. Peirce and highlighting some of the insights from a Peircean take on legal semiotics that may contribute to our understanding of the role of style in making meaning in law. It is argued that, for a Peircean analysis of law, three levels can be distinguished, from the 'surface structure' down to the 'deep structure'. It is at the middle level (that of the 'basic structure') that a semiotic approach can yield coherent insights in terms of style, by examining the symbols and metaphors that make for the expressibility of 'habits', namely experiencebased patterns of action and interpretation.
\end{abstract}

Keywords: law and culture; style; semiotics; pragmatics; C.S. Peirce

\section{Introduction}

Conceptions and uses of 'legal style' abound. We speak of lawyers' style in terms of language, of judicial style in terms of argumentative patterns and, notoriously, of style elements in comparing legal systems. These uses are difficult to refer to some common conceptual core. What is apparent, however, is that, in our usage, we tend to focus on the aspect of style related to perception, most often as a means of classifying the objects of our experience based on how they appear to us. Yet the other aspect - that of choices and (more or less conscious) efforts to make a certain kind of appearance - always lurks in the background, making a unified explanation even more problematic.

This paper looks at the concept of style from the perspective of legal semiotics. In fact, each of the uses mentioned above has found their reflections in semiotically informed legal studies. ${ }^{1}$ What a semiotic approach to the concept of style can offer for legal studies is a way of understanding how 'style' emerges in law and what makes it 'legal'. In what follows, we seek to explore the promises and limits of a specific current within semiotics initiated by C.S. Peirce and applied in the field of law most notably by R. Kevelson. We shall do so in two steps. The first part identifies the place of style in the structure of law as a system of signs, also situating it with reference to (a Mannheimian understanding of) the concept of culture. The second part deals with the conceptual links between law and style as appearing in the thought of Peirce, to highlight the elements of his theory that are useful for understanding how style works in law. Finally, we provide a summary picture based on these insights, linking it to those formulated in law and semiotics scholarship.

\section{Style and structure in legal culture}

What are we looking for when examining legal style? What is 'style' in law and how does it become 'legal'? As has been noted in the field of legal semiotics, law is 'a double semiotic system' (Jackson,

\footnotetext{
${ }^{1}$ On lawyers' style, see Jackson (1995, pp. 93-98); on the semiotic interest of argumentative patterns, see Balkin (1991); for a semiotic analysis of a specific legal culture, see e.g. Tiefenbrun (2007).

(c) Cambridge University Press 2019
} 
1985) in the sense that, within the legal system of signs, the attribution of meaning is directed by both the rules of language and those of the law itself. In so far as the latter are not inherent in language, the specifically legal character of any expression only appears in the context of communication and depends on the situations, means, actors and addressees in, by and to which it is applied (semiotic group) (Jackson, 1985). For instance, unless one wishes to argue for the existence of law as a separate language, with no reference to natural languages, one cannot show the difference between a judicial decision and a novel in terms of the grammar used, just as there is no difference between the judge's robe and an overcoat in terms of being clothes.

In the terminology of structural linguistics, the 'deep structure' and the 'surface structure' (see Chomsky, 1964) can be opposed here, with the insight that it is to the latter that various concepts of 'legal style' can be applied. In terms of the former, both stylistic differences and the 'legal' quality are impossible to grasp. Style in general, and legal style in particular, could then be investigated by focusing on surface characteristics (see Eco, 2004), using empirical methods. The inclination of Hungarian lawyers to use Latin terms or to omit definite articles when drafting legal documents are observations that can be made by comparing and contrasting various groups of texts. Based on that, the 'legal' genre might be distinguished from others.

Yet, already, the earliest accounts of (speech) style attribute specific (rhetorical) functions to the various stylistic types, which cannot be accounted for purely in terms of perceptions. Making sense of 'stylistic' phenomena presupposes sharing a framework of reference, within which meaning can be attributed to the differences observed. Such frameworks can emerge on the basis of experience or as results of choices and decisions. To come back to the example of clothing: one may perceive many differences between the judge's robe and one's own overcoat, and still not identify it as a sign or mistake it for a different one, if one does not know the 'code' directing the interpretation of signs within the given system. ${ }^{2}$

If we go beyond the field of law and attribute such frameworks (codes) to cultures in general (see Posner, 2004), then two levels of cultural communities can be distinguished: an explicit or 'overt' culture and an implicit or 'covert' culture. ${ }^{3}$ The overt culture can be described as the surface structure of the respective system of signs, while its covert counterpart as the characteristics of the deep structure. These latter often remain unreflected, even unconscious, and appear at the level of linguistic expression as metaphoric signs.

Stylistic individuality of the surface thus seems to be a transformed version of deep structure elements. ${ }^{4}$ What we typically find at the latter level is a system of schemes and patterns (of action), having almost unlimited ways of transformation at the surface level, according to the characteristics of the respective system of signs. A number of patterns and conventions have emerged through time, governing the creation and reception of signs, as well as their uses, sometimes without being reflected upon. In stylistic scholarship, these are often termed 'cognitive frameworks' or 'scripts'. ${ }^{5}$ It is these schemes that set the limits for the possible directions of interpretation and action, thus showing the determining influence of the deep structure. On a psychologising account, that influence may be explained with an instinctive, often unconscious, striving for safety and transparency. The increasing complexity and indeed intricacy of sign processes make it necessary to recur to simplified patterns of action, which are, as it were, condensed forms of historical experience, usually appearing in the form of metaphors, symbols or tropes (cf. Geertz, 1973, pp. 172-198). Law is no exception, being one of the symbolic dimensions of social action, with its simplifications serving orientation and interpretation.

\footnotetext{
${ }^{2}$ See e.g. H. Szilágyi (2005, p. 136), quoting a person who has misread the judges' dress code, saying 'I thought them priests'.

${ }^{3}$ For the distinction, based on the linguistic theory of W. von Humboldt, see Stepanov (1971), arguing that elements of the implicit (covert) culture differ among national cultures, each forming separate systems. When used for sign systems, the concept of culture does not have to be limited to nations or other particular groups (cf. Posner, 2004).

${ }^{4}$ On the correlation of deep and surface structures, shaping the style of the text, see e.g. Weinrich (1966).

${ }^{5}$ In terms of style, see Pethö (2011, p. 17) on the necessity for identifying the 'structure of meaning' (the conscious or unconscious model underlying the creation of any text, as a first step of interpretation).
} 
Moreover, even within the 'overt' culture, legal signs belong to a specific field, a subculture, and can be identified as such only by reference to a deeper level of signification. Using the previous example, it is within the 'overt' culture that one can observe how judges are recognised in court from their robes. Yet the use of that sign is not entirely based on a general cultural convention, but is at least partly governed by conventions inherent in the 'legal' subculture. While it is easily observed that certain people wearing a certain kind of outfit play a specific role in a given context, the question of why that happens can be only answered with reference to rules that form the deep level of signification. Part of the answer comes from such general conventions within a given culture such as the use of dressing to convey meaning, through colours, tailoring and other features. But, due to that generality, that is not where the subsystems of signs, the subcultures, can be found. The other part of the answer must then come from a higher level that is still below the surface. When acting as a judge, the judge is using his or her robe as a sign, but does not give an account of why and how (s)he is entitled to use it. Nor do judges make explicit the metaphoric character of their robes (as signs of power, separation and so on).

In the case of law as a system of rules, we find a structure comprising a network of alternatives of action. Choice among these alternatives is limited by the cultural context, the particular situation and the place of the individual in both of these. ${ }^{6}$ Yet, if the 'legal' quality of style cannot be grasped at the level of the deep structure, and nevertheless being perceived at the surface, and if law has got its own stylistic constraints influencing the surface structure, then it seems to be in order to describe these latter at a middle level. That level of signification, perhaps best termed the 'basic structure', already contains what may be regarded as possible ('legal') forms of action and whichever is going to become actual needs to fit into the framework thus constrained. 'Legal' patterns of action, and their emergence, are influenced by the cultural aspects of the given society. ${ }^{7}$ These latter, 'meta-juristic' elements, also parts of the basic structure, thus leave their traces on whatever is understood by 'legal style'.

Influences are not unidirectional, though. There is some kind of a feedback from the 'higher' levels of the system to the 'lower' ones as well. Codes of meaning-making are shaped by the very practice of communication making use of them. The patterns and conventions just mentioned condense such ever-changing practices of actualising and individualising. For instance, the fact that judges wear a certain type of robes will also constitute some kind of a constraint for further signification. If one wishes to express something through dressing, one will have to take that into account, both as a specific sign (that is now 'taken', i.e. one should not dress as a judge unless one wishes to be identified as a judge) and as part of a wider practice of using sartorial signs to refer to social roles.

Looking at the 'style' of law with the aim to identify and understand its 'tropes' and 'figures' does not therefore mean to seek to discover an abstract structure of ideas. The patterns that direct action and interpretation are based on experience, namely human reactions to the surrounding social reality, which are becoming increasingly 'dense' with the increasing complexity of sign processes that is due to the feedback. That reality does, without doubt, have its aesthetic as well as ideological dimensions, but the first thing to investigate is how the mechanism of signification works and it is here that C.S. Peirce's approach may prove helpful.

Unlike the structuralist analysis of signs, having its origins in the structural linguistics of F. Saussure and based on the distinction of 'signifier' and 'signified' (cf. Saussure, 2011, p. 133), Peircean semiotics examines the triadic relationship between the 'sign' (as a physical phenomenon), the 'object' (the

\footnotetext{
${ }^{6}$ Jackson $(1985 ; 1988)$ describes that in terms of a Greimasian (structuralist) 'narrative grammar', claiming that the choice between alternatives of action is more limited in law than in other types of discourse. Analysing trial cases, Jackson emphasises that what judges do is actually evaluating and selecting (fictitious, false or true) 'stories'. In doing so, they first decide about the credibility of narratives, which is determined by culture and social consensus. The 'truth' of a story is thus influenced by the already existing patterns, abstracted from earlier cases (similar to the one currently before the court). Therefore, whether a story is credible depends on how it fits into one of these narrative frames.

${ }^{7}$ See Mannheim (1982), with note 9 below.

${ }^{8}$ For an early example, see John Henry Wigmore's A Panorama of the World's Legal Systems (1928), in which photographic reproductions of architecture and sculpture are meant to illustrate how artistic style correlates with the 'style of law' in a given society.
} 
specific part of the world the sign refers to) and the 'interpretant' (the meaning of the sign, i.e. the effect it has on the mind interpreting it) (see Jackson, 1985). The last element of the model is important for us here, for two reasons. On the one hand, the interpretant highlights the element of perception that is key for understanding style. On the other hand, according to Peirce, the interpretant is a sign itself, with its own triadic structure, which emphasises the dynamic continuity of the sign process that is present in the functioning of style, too.

In terms of interpretation, the role of style is that, through it, a given sociocultural system is directing individuals' interpretive activity in a certain direction. At the surface level, that is informed by the primary (and explicit) objectives of the given social system; that is, here we are dealing with a conscious effort to direct interpretation. At the basic level, in turn, what governs the interpretation of signs are those patterns that constitute a 'community of experience' in the Mannheimian sense. ${ }^{9}$ In other words, the effect of the stylistic elements of the surface level depends on the meaning (interpretant) attributed to them by the recipients (interpreters). That, in turn, is based on their interpretive frameworks (described by Peirce's concept of 'habit'; see the next section). The totality of interpretive patterns (which can be described as a 'total cultural style' or 'worldview' of the given society) ensures that the social effects of signs remain homogeneous - that is, that the different objectives of specific subsystems do not scatter their use. ${ }^{10}$ Still, the attribution of meaning by the individual recipient is a necessary condition and it requires the surface structure of any utterance to fit into the particular framework governing the individual's interpretation. ${ }^{11}$ If that latter condition is not obtained, then the addressees will not be able to make sense of the message, which then cannot have any effect.

Condensed sets of experiences tend to appear through contrasts such as those of 'good' and 'evil' or 'right' and 'wrong'. It has been observed that, in the field of politics, metaphors and symbols play the role of simplifying intricate experiences that normally provoke fear or uncertainty. ${ }^{12}$ Political events are typically characterised by a level of complexity that evokes a human desire for a structured and transparent order (see Edelman, 1964). Yet, transparency and simplification are only part of the matter. Given that human actors do not generally have access to the set of complex experiences that brought about the pattern of action in question, they may be easily manipulated by those in a position to influence the use of signs. ${ }^{13}$

The tendency to govern the making of meaning seems to be even stronger in law (see Mannheim, 1982), given the function of legal rules to make their addressees conform to their provisions. Yet, addressees' likeliness to obey requires that they be capable of interpreting the rule, in terms of form as well as content. This highlights that it is not only the form (style) of the message that has an impact

\footnotetext{
${ }^{9}$ Mannheim, too, emphasised the influence of the deep structure on style (as part of the culture). On his account, experiences of a given period and nation are condensed into a 'community context of experience', i.e. a framework of action and interpretation. These 'contexts of experience' then enable the interpreters to grasp the content of cultural products in a collectively valid way. Thus, sociocultural objects are examined in a homogeneous dimension, allowing an effective dialogue between interpreters. Throughout that dialogue, the 'context of experience' provides the common denominator, helping to limit the (virtually unlimited) number of possible interpretations. For Mannheim, examining style means seeking to get an insight into the worldview of a particular period, which, however, shows different faces, depending on the aspect (art, religion, politics, etc.) through which it is approached (cf. Mannheim, 1982, p. 92).

${ }^{10}$ As Mannheim (1982, p. 92) puts it, the 'set of experiences' underlying different social objects is the same, making 'the same "spirit" [express] itself in these differing cultural objectivations'.

${ }^{11}$ Cf. Bencze's (2015) interesting example of the 'breach of style' from the field of judicial reasoning. He argues that, due to the conventional use of certain ways of editing and means of legal argumentation, judicial reasoning follows a more or less uniform style. In cases of departure from that received style, one may suspect that the substance of the reasons offered is unsatisfactory (either insufficient or irrelevant), since a different style indicates that the decision made by the judge cannot be justified in the 'conventional way'. That, to be sure, does not necessarily mean that the judgment is substantively wrong. Studying such cases of uneven style may nevertheless provide a 'diagnostic device' for highlighting the necessity for further investigations concerning a particular judgment; see Bencze (2015, pp. 131-138).

${ }^{12}$ Such interpretive frameworks are particularly frequent in religion and politics, the fields traditionally linked to nonrational action (cf. Edelman, 1964, pp. 178-180).

${ }^{13}$ It has been argued, however, that examining metaphors may lead to that sort of political knowledge; cf. Miller (1979).
} 
on the situation, but also the given circumstances may enforce a modification of the form. ${ }^{14}$ Thus, frameworks of action and interpretation cannot be regarded as some constant (and intuitively accessible) point of departure but, due to the circumstances, further layers of meaning appear on them (as a result of the dynamic functioning of signs). ${ }^{15}$

One may describe the legal system of signs, too, as one directed at the production of a structure of domination, based on the influence of power. In analysing the legal discourse, Van Fleet (2011) used one of the Lacanian types of discourse - the 'Master Discourse' - as an analogy. The underlying parallel is that of the relationship between master and subject, with the latter lacking the necessary amount of experience and therefore being compelled to obey the master's commands with no possibility of raising questions (cf. Van Fleet, 2011, pp. 60-61). Looking at the sign processes of law, however, it needs to be pointed out that the interpretant still has a key role. In the triadic relation of the legal system of signs, the interpretant may bring about a gap, often frustrating the law's efforts to dominate. The reason for that is the connection between the meaning of a sign and the principles and requirements of other systems of signs (see Van Fleet, 2011, pp. 57-72), namely the fact that the experience underlying the principles governing a person's actions is a complex one, not only legal, but also moral, cultural, etc. Otherwise put, it is due to the interpretant that the law as a system of signs fits into a broader cultural framework. The various social and cultural manifestations of a 'spirit', shaped through a series of experiences, are therefore the products of continuous interpreting activity.

The role and functioning of the production of such frameworks of interpretation, the making of meaning in law through style, may perhaps be adequately described on the basis of the pragmatist semiotics of Charles S. Peirce. There are three features of Peirce's theory that seem to be very close to the above considerations. First, according to Peirce, the production of new signs is limited (by the 'deep structure') in terms of what signs to create and how to do that. Second, the cognitive and interpretive capacities of the interpreter play an important role in the functioning of signs. And, third, the concept of 'habit' (customs, schemes, patterns) is of key importance in understanding the increasing complexity of sign processes. In the following sections, we first summarise what elements of the Peircean tradition of semiotics seem useful in conceptualising style, then we look at the insights offered by that tradition in the field of legal semiotics.

\section{A Peircean approach to style}

As has been pointed out above, if law has got a 'style', then its importance lies in the effect it has through directing human action. That insight is rather close to the key tenet of Peircean pragmatism, according to which the content of any concept consists in its influence on human behaviour (cf. CP 5.438). ${ }^{16}$ In a similar vein, one of the leading legal semioticians of the twentieth century, Roberta Kevelson, argued that legal practice and legal discourse are, in fact, the best illustrations for the essence of pragmatist theory (see Kevelson, 1986, pp. 355-371) and not only because lawyerly thinking had a considerable role in shaping Peirce's thought. ${ }^{17}$

\footnotetext{
${ }^{14}$ See Lasswell (1965, p. 66): 'When fighting, the physical material of utterances is very dense, sometimes resembling the model of a missile.'

${ }^{15}$ In contrast, the rigid structure of stylistic elements on the surface may indicate the tendency of the social regime to eliminate the influence of interpretive habits on the interpreters (preventing, as far as possible, the addressees of the law from intuitively realising the inadequacy of a given provision or the regime as a whole).

${ }^{16}$ References to Peirce's works give volume and paragraph numbers of Collected Papers of Charles S. Peirce (Hartshorne and Weiss, 1932-1958), abbreviated as 'CP', and The Essential Peirce (Houser and Kloesel, 1992), abbreviated as 'EP'.

${ }^{17}$ Pragmatism as a philosophical current appeared in the US towards the end of the nineteenth century. It was in his 1878 paper, 'How to make our ideas clear?' (CP 5.388-410), that Peirce first introduced the concept into philosophical discourse. According to the central tenet of pragmatism, truth means usefulness, i.e. the truth of a judgment consists of its practical applicability. However, Peirce claimed that the name 'pragmatism' was actually coined by a lawyer, Nicholas St. John Green, one of the jurists in the Metaphysical Club, through whom Peirce's conception contributed to setting the theoretical basis to American legal realism (cf. Kevelson, 1987, p. 9). Peirce described him as one of the most interesting members, reputed as a learned and skilled lawyer. His influence on Peirce's conception can be detected primarily in his emphasis on the importance of Alexander Bain's definition of 'belief, which he urged to apply in connection with reality.
} 
Although Peirce constructed no specific theory of style, his semiotics nevertheless allows the reconstruction of a teleological concept of style that helps to answer the question of how elements of style can have an effect: what is the process of style and what is the goal of that process? In other words, a Peircean approach can contribute to the understanding of the link between style and the interpretant, thereby offering a new perspective on the functioning of style. To lay that out, we need to look at three of the key themes of pragmatist semiotics: (1) the dynamic and teleological character of sign processes ('semiosis'); (2) the stages of human thought ('belief, 'doubt' and 'habit'); and (3) Peirce's phenomenological categories ('Firstness', 'Secondness' and 'Thirdness'). This section summarises the insights Peircean semiotics can offer us in these fields, together with those of twentieth-century legal semiotics.

\subsection{Semiosis as a dynamic and teleological process}

As we have seen, pragmatist semiotics describes semiosis as a dynamic process comprising three elements: the 'sign', the 'interpretant' and the 'object'. Thus, the sign process works not in isolation, but is extended to the context in which it can come to have effect, namely to its sociocultural relations. That triadic process then keeps on regenerating itself, thereby producing further signs as the result of continuously interpreting new information (cf. CP 2.230-232). Throughout that process, the interpretant (i.e. the meaning of the sign) brings about new signs, while being limited in what signs and how it can be created. ${ }^{18}$

Moreover, Peircean semiotics is also teleological in the sense that the continuous production of signs takes place for the sake of achieving a certain goal: knowledge. That is, however, never free from problems, as everything in the process depends on the interpreter's capacity to interpret correctly. One should also bear in mind that it is through that continuous process of interpretation that signification is becoming increasingly complicate. On Peirce's account, then, signs may be misleading and human thinking fallible. ${ }^{19}$ Some patterns (that proved to be useful in similar cases in the past) serving as a point of orientation for interpretation, and hence for human action, are necessary.

The use of these patterns can be best described through Peirce's concept of 'abduction'. Although his use of the term was not quite consistent, from the perspective of style, we may understand it both as a weak form of inference and a way of generating ideas (for the distinction, see Paavola, 2005). In the first case, abduction works through analogy: if we know that a certain feature characterises a group of objects and see that a given object shares that feature, we may suspect that it belongs to that group (cf. CP 2.623). In the second case, the starting point is the observation of something unexpected and the new idea is a possible explanation for it (cf. CP 5.189). The first way of using abduction appears, for instance, in the classificatory uses of 'legal style', while we may see the second one at work in cases where a 'breach of style' is perceived.

Peirce gives an outline of how these schemes are generated and also how they work. In pragmatist terminology, these patterns of schemes of action are 'habits', produced through the process called 'the chain of thinking', which comprises three steps: 'belief, 'doubt' and 'habit'.

According to Bain, 'belief' is the condition that makes the individual ready for action (cf. CP 5.12, quoted by Colapietro, 2008, p. 226, and Bergman, 2009, p. 15). Concepts and expressions can be understood only by way of investigating and examining their practical consequences (James, 1907, p. 147). On the pragmatist account, the world is created in a way that it is only through the sphere of publicly verifiable things and phenomena that any statement concerning an utterance can be successful. As we are going to see presently, however, Peircean pragmatism does leave some role to elements that cannot be verified empirically.

${ }^{18}$ As Peirce (CP 2.230) put it: 'the Sign and the Explanation together make up another Sign, and since the explanation will be a Sign, it will probably require an additional explanation, which taken together with the already enlarged Sign will make up a still larger Sign.'

${ }^{19}$ In his 1868 paper, 'Some consequences of four incapacities', Peirce explains how cognitive and interpretive capacities are limited, discussing what he regards as the four basic incapacities of human beings (lack of introspection and intuition, no capability to think without using signs and 'no conception of the absolutely incognizable'; CP 5.266). 


\subsection{The 'chain of thinking'}

On a Peircean account, the functionality of human thinking means that each person acts on motivations whose effects are known to correspond to the expectations that form the starting point of human action. Thus, individuals act on the basis of beliefs that have been tried and checked, either personally or socially. The function of thinking is to produce belief (cf. CP 5.396), which then determines the way for action. The thought content of beliefs is conveyed to human beings primarily by way of linguistic expression. That said, beliefs that form the basis of frameworks of experience are by no means conscious. More specifically, they cannot be described as being conscious of an action, or as a state of mind, but the inclination to act and to function (cf. Colapietro, 2008, p. 226). Yet, in certain situations, one cannot decide in advance what the right way of action is, since the effects cannot be foreseen. That is the state of doubt, which puts the mind to work in spite of the momentary uncertainty.

In such cases of doubt, the mind recalls the multiplicity of sensations experienced so far from its inventory of memories (CP 5.395) and selects those patterns of action that make it possible to adapt to the circumstances that created doubt. It is through the above process that humans shape their world, as a system of signs, making it increasingly complex, with patterns of action based on the production of habits. It is thus characteristic of belief that it contributes to the creation of habits (CP 5.398). These latter are, in turn, schemes of action generating the regular occurrence of events. These schemes, however, do not appear in their original form, but take on additional meanings through the sign processes, with these meanings resulting from the underlying multiplicity of experience. It is in this way that meanings become increasingly dense ('symbols grow', cf. CP 2.302).

The third and final stage of the process is the emergence of units through the systematisation of patterns of action. These are the habits, which are in fact the condensed forms of experience-based schemes of action. Habits can be identified according to their way of directing behaviour, namely how and when they motivate specific actions, aimed at specific (recognisable) results (cf. CP 5.400).

\subsection{Peirce's phenomenological categories}

As has been recently argued by several scholars, understanding Peirce's phenomenological categories is of key importance for any attempt to make his semiotics fruitful for the study of law (see Pearson, 2008a; 2008b; Hausman, 2008; Colapietro, 2008). These categories all refer to experience and represent the level of complexity of a given sign process as well as that of the world as a system of signs. Peirce distinguished three categories, which he termed 'Firstness', 'Secondness' and 'Thirdness', respectively. Firstness refers to the 'quality of sensation', directed at individual and unrelated things and phenomena (cf. CP 1.356-357). Secondness, 'actuality', presupposes a certain relationship between two things, even though that relationship is still not conscious (cf. CP 1.358). Finally, Thirdness is 'a category of continuity' of the interpreting activity (cf. CP 1.361). Law can be considered to belong to that latter category. ${ }^{20}$

The distinctive element of Thirdness is the appearance of a third factor (the interpretant) in the functioning of signs, ${ }^{21}$ which is capable of making a connection between two things that are apparently unrelated. ${ }^{22}$ It is through the making of these connections that the interpretive community can create increasingly complex signs. Moreover, it is also at that level that symbolic and metaphoric

\footnotetext{
${ }^{20}$ 'Law as an active force is second, but order and legislation are third' (CP 1.337).

${ }^{21}$ See Hausman's (2008, p. 211) example of the dropped coin. If someone drops a coin on the street (without realising it) and someone else comes along and picks it up, then there is a twofold relation. The first relation exists between the person dropping the coin and the coin itself, and the second between the person finding the coin and the coin. In the first case, we are dealing with Secondness, due to the lack of being conscious of having dropped the coin. There is no mental relation between the person dropping the coin and the one finding it, as it is only through the object (the coin) that they are in an indirect relation.

${ }^{22}$ Thirdness is an aspect of cognition and experience bridging the gap between the 'absolute first and last' (cf. CP 1.337: 'The beginning is first, the end second, the middle third. The end is second, the means third').
} 
thinking can appear, since the associative making of meaning by the interpretant is guided by already existing customs and traditions. Using these categories, Peirce tried to emphasise that it is through the interpreting activity that meaning can be attributed to the world surrounding us. ${ }^{23}$

There have always been certain rules for that process of attribution of meaning, for it is not indifferent what pattern one uses for interpreting a given thing or phenomenon. As we have seen, the chain of experience related to the respective thing or phenomenon plays a major role in shaping these patterns of interpretation. Hence, the importance of customs ('habit') and traditions, as well as the limited freedom of the interpretant in attributing meaning. Accordingly, it is due to the underlying chain of experience that a legal act or legal text will be interpreted in a different framework than everyday behaviour or literary works. The law belongs to Thirdness, because it needs to be interpreted to be able to have an effect on its environment. In legal sign relations, the relation between the interpretants is usually conscious (e.g. in cases of gifts, contracts or marriages) and not established by mere chance (as in Secondness). Also, in order to make an impact, the legal system of signs needs to have characteristically legal patterns, which direct the activity of the interpreters in the way corresponding to the ends of law. Although the Thirdness of the legal system of signs works at the surface level, processes below that level, too, need to be taken into account. These latter have an impact on the very characteristics of law's Thirdness, namely how legal signs are interpreted and how these frameworks of interpretation ('habits') are rooted in experience. Even though law is Thirdness in a primary sense, its surface level is based on Firstness and Secondness.

With the above phenomenological categories being based in experience, Peirce distinguished a further category - one that refers to the stage preceding semiosis. That one he called 'Ground' and, unlike the three others, it is not one of experience, but provides an instinctive direction for the attribution of meaning by the interpretant. ${ }^{24}$ Ground comprises principles and ideas, which, while non-rational, are nevertheless capable of becoming rational in sign processes (cf. CP 1.358). According to Peirce, that intuitive capacity ${ }^{25}$ is human beings' share in the work of Creation.

Ground is inaccessible for any stylistic analysis, given that it has no connections to experience (i.e. there is no 'condensed', symbolic knowledge in it), although it is covered by layers of meaning. ${ }^{26}$ Its elements still are of importance in terms of style, since the verified and condensed patterns of action, which form the basic structure, are permanent because they have been checked against those ideas of the Ground.

\section{A pragmatist semiotic concept of legal style}

From the dynamic character of semiosis and the belonging of law to the category of Thirdness, it follows that the legal system of signs is one where right interpretation (the one corresponding to the pragmatic end of law as a system of norms, i.e. regulating human behaviour) depends on the interpreter's recognition of the legal quality of a given action. Thus, interpretive patterns serving the aim of simplification appear in law as well. Their complex, the 'habit' that is characteristic of law, needs linguistic expression to be communicated to the interpreters. That is, legal 'habit' appears in legal 'style'. Yet, due to the dynamic and open nature of law as a system of signs (cf. Section 3.1 above), it is not only pure 'legal' experience that plays a role in the creation of legal 'habit': other sorts of social, cultural or economic experience all have their impact. The concept of style derived from Peircean semiotics thus fits with the cultural definition of style.

That also corresponds to an insight formulated by Roberta Kevelson, one of the chief exponents of the pragmatist current within twentieth-century legal semiotics. In her book, The Law as a System of

\footnotetext{
${ }^{23}$ The 'reliable method' of interpreting phenomena was one of Peirce's core interests. It was in connection with it that he described the method of abductive reasoning (see Paavola, 2005). On the relationship between forms of inference and the categories, see Staat (1993).

${ }^{24}$ In a passage (CP 6. 467), Peirce calls them the 'Sign's Soul', which function as links between the object of the sign and the mind of the interpreter.

${ }^{25}$ Even the exploratory use of abduction, the instinct of right reason, is based on that (cf. Sebeok and Sebeok, 1980, p. 44).

${ }^{26}$ As Peirce put it: 'a pure idea without metaphor or other significant clothing is an onion without a peel' (EP 2.392).
} 
Signs (1988), Kevelson seeks to grasp the nature of the legal system of signs. She argues that, in the case of the law, experience-based habits need to continuously align themselves with the changing needs of the society surrounding them, since law is a dynamic system of signs with the role to represent values corresponding to social needs and principles of action. Legal codes (signs) are, then, 'mirrors of society', with the legal discourse being a symbolic kind of discourse. That relates to the notion of 'condensing' experience: the law produces symbols from its verified knowledge, thus providing patterns of human behaviour. ${ }^{27}$ In doing so, law is influenced by schemes of experience gained in other fields, such as habits that have emerged in the economy, the family or other cultural institutions (Kevelson, 1988, pp. 9, 14-15). Neither the legally relevant forms of behaviour (e.g. making a contract) nor their definitions or qualifications (the criteria of validity) are 'legal' in the sense that they would be created by the law. What the law qua law does within that process is to formulate certain standards with reference to certain social practices, in a form that is accessible to its addressees.

The determining influence of style on interpretation also appears in the pragmatist semiotic concept of style. According to Peirce, 'habit' is a determining factor ${ }^{28}$ in the process of signification. Thus, the basic structure of the legal system of signs consists of 'habits', the persistence of which is guaranteed by stylistic elements, such as metaphors or symbols. ${ }^{29}$

Peirce's concept of symbol is characterised not so much by arbitrariness or conventionality, but by its relation to 'habit'. For him, symbols are signs that fuel the emergence and shaping of ever-changing habits ('the virtue of a growing habit', cf. Nöth, 2010, p. 82). In law, these 'habits' need to be maintained, since the law, as an open and dynamic system of signs, modifies its frames and borders according to the needs to change, while it also needs to offer patterns of orientation, so the interpretants can accommodate past principles and insights to the requirements of the present and interpreters can draw some conclusions as to the expectations of the future on the basis of their knowledge. ${ }^{30}$

The phenomenological categories are also helpful in highlighting the limits of stylistic analysis. Peircean semiotics teaches us that what is accessible for such investigations needs to be based on past experience (the discovery of 'habits'), with its (present) impact being perceivable. For Peirce, law (as a principle) is purely mental content and what legal rules do is to communicate that (ideal) legal content through linguistic expression. As he put it, 'right is a matter of law, and law is a matter of thought and meaning' (CP 1.475). Given the 'incapacities' described by Peirce (cf. note 19 above), there is no way to get to knowledge directly.

Moreover, the interpretation of law through the examination of its style is necessarily limited due to the complexity of law as a system of signs. ${ }^{31}$ A stylistic analysis is not going to provide us with an explanation concerning the 'true' or 'essential' meaning of a legal sign, based on some common network of meanings. What can be grasped this way is rather the effect of the thought content expressed through style. The impact of law on its environment takes place through the attribution of meaning and law exerts that influence through its style. What the examination of style can contribute to our understanding is to show by what means the law governs its own interpretation, seeking to bring about meanings the effects of which comply with the general aims of its system, but also the ways in which the very acts of interpretation set limits to that influence.

\footnotetext{
${ }^{27}$ Here, Kevelson (1988, p. 11) quotes Oliver Wendell Holmes, who regarded the Constitution as the most precise representation of a nation's legal knowledge, also calling it 'an experience'.

${ }^{28}$ Peirce describes 'habit' using the terms 'regularity', 'general rule' and 'acquired law' (cf. CP 2.292).

${ }^{29}$ In the sense of Peirce's metaphoric speech, a sign is not something artificial, but a living conception, rooted in practices such as communication and cognition (cf. Bergman, 2009, p. 79).

${ }^{30}$ Another parallel here is with the interpretive concept of 'recursiveness', developed by Norbert Wiener in a cybernetic context (see Wiener, 1948; 1950), and later applied in various fields, from ethnology to political science. Iser (2000, pp. 91, 113) regards recursiveness as a 'creative force', which makes it possible for the system to maintain itself through the adaptation of earlier patterns, as well as the emergence of higher-order complex systems.

${ }^{31}$ It is at that point that Eco finds a parallel between Peirce's (pragmatist) and Hjelmslev's (structuralist) theories. According to Hjelmslev (1953), linguistics can have no pretention to being scientific beyond certain limits, determined by the 'content'. That latter is reflected by the signs used for expressing it, which therefore cannot be 'complete'. The continuum, before taking on the form of the substance through language, is everything and nothing and therefore eludes all determination' (Eco, 2000, p. 52).
} 


\section{Conclusion}

Seeking to find a perspective that allows a 'synoptic' approach to legal style, this paper started from the insight that, in order to do so, one needs to identify a middle level between the 'surface' and the 'deep structure' of law as a system of signs. That is necessary, since the deep structure, on the one hand, does not contain elements that would be accessible to any stylistic classification (or that could be perceived as 'legal'). On the other hand, the surface, where 'style' and 'law' are perceived, does not allow a unified description of either the concept or the functioning of legal style.

The doctrine of semiotics developed by Charles S. Peirce does offer such an intermediary level (which we termed 'basic structure') through the concept of 'habit'. We hope to have shown that the three levels thus distinguished prove fruitful in understanding style within the semiotic system of law. First, there is its surface structure, with the pragmatic functions of stylistic elements depending on the respective field of law. Within a domestic legal system, for instance, it is at that level that we can grasp the difference between, say, private and public law: the former is meant to establish standards for interactions among equals (mostly private individuals and their associations), while the latter deals with relations involving the state and its agencies. From the perspective of style, we can observe, among others, differences in terms of the linguistic structure of statutes or how specific terms are interpreted (e.g. 'right' referring to possible ways of actions and conditions of validity in private transactions, and expectations and limits to state actions in constitutional or administrative law). The basis of these interpretations, in turn, can be found within the basic structure as 'condensed' patterns and schemes of action ('habits'), based on experience. It is here, for instance, that the concept of 'validity' or 'normativity' can be grasped. The working mechanism of the basic structure is partly similar to the third, deep structure, as its way of functioning often remains unreflected by the interpreters. The difference between the two is that the deep structure contains all the preconditions for the emergence of habits, such as the rules of natural languages and other forms of thinking and communication.

A unified approach to style in law seems possible only in terms of the basic structure. There, the experiential background of habits can be uncovered through the symbols and metaphors that make for their (condensed) linguistic expression. The reality of a symbol was considered by Peirce to consist of the symbol's fitting to the facts of reality, while having an influence on the thought and behaviour of those interpreting that reality (cf. CP 4.447). That insight invites to situate style in relation to the concept of culture (for which the work of Karl Mannheim provides a source of inspiration). In Peircean terms, it is the interpretive activity of human beings that produces the whole of culture, within which 'legal' elements are then separated. Style functions within the framework of interpreting cultural contents and thus contributes to the (re)production of culture, including legal culture. That process can be described with the Peircean chain of belief, doubt and habit.

In understanding style in law, habit can be regarded as the abstraction of experience-based rules and practices, which are also conditioned by certain anthropological facts, human capacities and incapacities that determine the deep structure. Yet, the application of, and reflection on, these rules and practices happens through the use of signs that appear at the surface. That use, then, is 'distilled back' into further abstractions, thus bringing about an ever-changing and still relatively stable system of meanings, which can be summarised in the concept of legal culture.

By focusing on these sign processes, both individually and as complex systems, a semiotic approach to legal style has got the promise of a common methodological basis, useful for micro and macro analyses alike. Whether comparing the 'thinking styles' of French and English law (as done e.g. by Catherine Valcke in the present volume) or using stylistic analysis as a diagnostic device (see e.g. Bencze, 2015), it is possible to go beyond the level of the surface structure, identifying patterns and formulating explanations within the same, semiotic, conceptual framework.

\section{References}

Balkin JM (1991) The promise of legal semiotics. Texas Law Review 69, 1831-1852.

Bencze M (2015) Az ítéleti indokolások diagnosztikája - az ítélkezési stílus vizsgálatának jelentősége [The diagnostics of judicial reasoning: the importance of researching judicial style]. In Szabó M (ed.), A jog nyelvi dimenziója [The Linguistic Dimension of Law]. Miskolc: Bíbor, pp. 129-139. 
Bergman M (2009) Peirce's Philosophy of Communication: The Rhetorical Underpinnings of the Theory of Signs. London/ New York: Continuum.

Chomsky N (1964) Current Issues in Linguistic Theory. The Hague: Mouton.

Colapietro V (2008) Peircean semeiotic and legal practices: rudimentary and 'rhetorical' considerations. International Journal for the Semiotics of Law 21, 223-246.

Eco U (2000) Kant and the Platypus: Essays on Language and Cognition. London: Vintage.

Eco U (2004) 'On style'. In Eco U (ed.), On Literature. Orlando, FL: Harcourt, pp. 161-179.

Edelman M (1964) The Symbolic Uses of Politics. Urbana, IL: University of Illinois Press.

Geertz C (1973) The Interpretation of Cultures: Selected Essays. London: Hutchinson.

H. Szilágyi I (2005) The Roma way - comparative legal studies: comparative law, sociology and anthropology. In H. Szilágyi I and Paksy M (eds), Ius unum lex multiplex: Studia Z. Péteri dedicata. Budapest: Szent István Társulat, pp. 129-150.

Hartshorne C and Weiss P (eds) (1932-1958) Collected Papers of Charles S. Peirce, 8 vols. Cambridge, MA: Belknap.

Hausman CR (2008) Charles Peirce's categories and the growth of reason. International Journal for the Semiotics of Law 21, 209-222.

Hjelmslev L (1953) Prolegomena to a Theory of Language. Baltimore: Indiana University Press.

Houser N and Kloesel C (eds) (1992) The Essential Peirce: Selected Philosophical Writings. Bloomington, IN: Indiana University Press.

Iser W (2000) The Range of Interpretation. New York: Columbia University Press.

Jackson B (1985) Semiotics and Legal Theory. London: Routledge and Kegan Paul.

Jackson B (1988) Law, Fact and Narrative Coherence. Roby, Merseyside: Deborah Charles.

Jackson B (1995) Making Sense in Law: Linguistic, Psychological and Semiotic Perspectives. Roby, Merseyside: Deborah Charles. James W (1907) Pragmatism: A New Name for Some Old Ways of Thinking. Cambridge, MA: Harvard University Press.

Kevelson R (1986) Semiotics and methods of legal inquiry: interpretation and discovery in law from the perspective of Peirce's speculative rhetoric. Indiana Law Journal 61, 355-371.

Kevelson R (1987) Introduction to the First Round Table on Law and Semiotics. In Kevelson R (ed.), Law and Semiotics. New York: Plenum Press, pp. 1-24.

Kevelson R (1988) The Law as a System of Signs. New York: Plenum Press.

Lasswell HD (1965) Style in the language of politics. In Lasswell HD and Leites N (eds), Language of Politics: Studies in Quantitative Semantics. Cambridge, MA: MIT Press, pp. 20-39.

Mannheim K (1982) Structures of Thinking. London: Routledge and Kegan Paul.

Miller EF (1979) Metaphor and political knowledge. The American Political Science Review 73, 155-173.

Nöth W (2010) The criterion of habit in Peirce's definitions of the symbol. Transactions of the Charles S. Peirce Society 46, 82-93.

Paavola S (2005) Peircean abduction: instinct or inference? Semiotica 153, 131-154.

Pearson C (2008a) Beyond Peirce: the new science of semiotics and the semiotics of law. International Journal for the Semiotics of Law 21, 247-296.

Pearson C (2008b) Introduction to the Special Issue on Peircean semeiotic. International Journal for the Semiotics of Law 21, 201-208.

Pethö J (2011) Alakzat és jelentés. Az alakzatok stílus-és jelentésképző szerepe a szövegben. [Figures and Meaning: The Stylistic and Semantic Role of Tropes in the Text]. Budapest: Tinta.

Posner R (2004) Basic tasks of cultural semiotics. In Withalm G and Wallmannsberger J (eds), Signs of Power - Power of Signs: Essays in Honor of Jeff Bernard. Vienna: INST, pp. 56-89.

Saussure F de (2011) Course in General Linguistics. New York: Columbia University Press.

Sebeok TA and Sebeok JU (1980) 'You Know My Method': A Juxtaposition of Charles S. Peirce and Sherlock Holmes. Bloomington, IN: Gaslight.

Staat W (1993) On abduction, deduction, induction and the categories. Transactions of the Charles S. Peirce Society 29, 225-237.

Stepanov Y (1971) Semiotika [Semiotics]. Moscow: Nauka.

Tiefenbrun SW (2007) The semiotics of women's human rights in Iran. Connecticut Journal of International Law 23, $1-81$.

Van Fleet P (2011) Tarski, Peirce and truth-correspondences in law: can semiotic truth-analysis adequately describe legal discourse? In Broekman JM and Mootz FJ (eds), The Semiotics of Law in Legal Education. Dordrecht: Springer, pp. 57-73.

Weinrich H (1966) Linguistik der Lüge. Heidelberg: Schneider.

Wiener N (1948) Cybernetics. Cambridge, MA: MIT Press.

Wiener N (1950) The Human Use of Human Beings - Cybernetics and Society. London: Eyre and Spottiswoode.

Wigmore JH (1928) A Panorama of the World's Legal Systems. Saint Paul: West Publishing Company.

Cite this article: Bor B, Könczöl M (2019). Towards a semiotic theory of style in law: a Peircean approach. International Journal of Law in Context 15, 263-273. https://doi.org/10.1017/S1744552319000272 